\title{
Comparison of Chinese and Foreign Medical Students Performance in Pathophysiology Classes
}

\author{
Kangheng Wang1, Yu Zhang1, Dashan Li' ${ }^{1}$ Qian Zhang', Sah Arun Kumar ${ }^{2}$, Xiaochun Peng3 \\ ${ }^{1}$ The First Clinical Medical College of Yangtze University, Jingzhou, China \\ ${ }^{2}$ Yangtze University, Jingzhou, China \\ ${ }^{3}$ Department of Pathophysiology, Health Science Center of Yangtze University, Jingzhou, China \\ Email: ^Pxcwd789@sina.com
}

How to cite this paper: Wang, K. H., Zhang, Y., Li, D. S., Zhang, Q., Kumar, S. A., \& Peng, X. C. (2019). Comparison of Chinese and Foreign Medical Students Performance in Pathophysiology Classes. Creative Education, 10, 3255-3269. https://doi.org/10.4236/ce.2019.1013249

Received: October 23, 2019

Accepted: December 2, 2019

Published: December 5, 2019

Copyright $\odot 2019$ by author(s) and Scientific Research Publishing Inc. This work is licensed under the Creative Commons Attribution International License (CC BY 4.0).

http://creativecommons.org/licenses/by/4.0/

\begin{abstract}
In recent years, many international students have come to our college to receive medical education. This study aimed to compare learning skills between Chinese and foreign medical students. This will help us to formulate a more scientific and efficient teaching method, as well as to improve the level of medical education in our college. Pathophysiology classes were used as a measuring tool. We combined a questionnaire survey and teachers' experience to analyze and compare the performance of Chinese and foreign medical students. One hundred eighty Chinese and 120 foreign students were selected as subjects. The data of the questionnaires collected was analyzed with Sigma Stat 2.03 and Sigma Plot 12.5 software. Chi-square test was used for the comparison between the two groups. We found noticeable differences in cultural background, teaching style, learning habits, practical ability, and teacher-student interaction. Students should learn from their peers, learn the strengths of others so they can improve on their weaknesses. This approach can achieve a more practical teaching experience and will improve the overall quality of education.
\end{abstract}

\section{Keywords}

Pathophysiology Teaching, Contrast, MBBS Students

\section{Introduction}

Since the beginning of the century, more and more international students are coming to China to receive medical education. This phenomenon is due to the ${ }^{\star}$ Corresponding author. 
rapid development of Chinese advances in healthcare, the popularization of higher education, and the continuous expansion of international exchanges. Pathophysiology is a transitional subject between basic medicine and clinical medicine. Solid knowledge in this subject is necessary to learn clinical specialties. Therefore, Zhang (2012) considered it is of considerable significance to improve the quality of education in pathophysiology. The Teaching and Research Department of Pathophysiology in our college is responsible for providing medical education to international students while still teaching to undergraduate Chinese medical students. Zhao (2011) believed very important, so this study aims to do a comparative analysis of the teaching of Chinese and international medical students to obtain information for improving the learning experience of both parties.

\section{Methods}

\subsection{Study Design}

Self-assessment was conducted through a questionnaire, and the comparative analysis was made using the students learning behaviors. The differences between the two were analyzed according to the teacher's teaching experience. Finally, we proposed some improvement for both Chinese and international students.

\subsection{Study Group}

The largest group (90\%) of international students in our college comes from Pakistan, while $10 \%$ are Nepalese. In both countries, students graduate from medical school with an MBBS (Bachelor of Medicine \& Bachelor of Surgery) degree. In contrast, Chinese medical students receive a degree in clinical medicine when they finish medical school. In this research, 180 Chinese and 120 MBBS students were selected as subjects. They were junior students who had already studied all the basic medical subjects like anatomy, cell biology, physiology, pathology, pharmacology, biochemistry and molecular biology.

\subsection{Measurement}

The questionnaire was based on the teaching methods of pathophysiology and student's learning habits. The questionnaire was divided into four parts: pre-class, theory, experimental, and after-class. As for teaching methods, our college adopts a combination of traditional teaching with a new curriculum that introduces CBL (Case-Based Learning) and encourages student to participate. To cover most of the teaching activities and student's learning process; the questionnaire included 22 objective multiple-choice questions, 15 judgment questions, and two subjective questions. The Chinese-English translation of the questionnaire was considered carefully.

The questions and answers in the questionnaire were the following:

- Do you prepare before class (yes/no/sometimes)?

- Do you review the material and the time $(2 \mathrm{~h} / 1 \mathrm{~h} / 0.5 \mathrm{~h} /$ never $)$ ?

- What is your preference of classroom format (independent learning/teacher's 
lectures/comprehensive discussion of chapters/combining the three methods above)?

- What is your preference of lecture-style (multi-media/blackboard-writing/ combination of the two)?

- If a doubt/confusion arise during class, do you seek a response (ignore/ask the teacher directly in class/discuss with classmates after class/consult with the teacher after class)?

- What are your attitudes towards classroom interaction (positive/neutral/ negative/indifferent)?

- How do you take notes (write down all the key points/write down doubts/ don't take notes)?

- What is your method to review the learning material (read the textbook/do exercises/online course)?

- How do you search for references (browser search/search with professional database)?

- How do you connect the knowledge of pathophysiology (can't/can/need reference)?

- How do you relate pathophysiology to other disciplines (can/never do it/need teacher's guidance)?

- How much time do you spend in case analysis teaching (before class/in class/does not matter)?

- What is your attitude towards students' presentation in class (positive/negative/ neutral)?

- Are you willing to show in class (positive/negative/incompetent)?

- Which model of classroom presentation do you prefer (work alone/teamwork)?

- Do you have any team division preference (collect information/show on stage/raise questions)?

- What is your attitude towards students' sharing (accept completely/accept selectively)?

- Is there a chapter test requirements (yes/no)?

- What is your attitude towards an unexpected experimental result (look for reasons actively/follow the experimental instruction)?

- What is your attitude towards experimental recording (copy the experimental instruction/analysis based on the results objectively)?

- What are the key issues to improve the school-academic level (teaching concepts/teachers' level/education resources/others)?

- What are the key points to improve the quality of classroom teaching (teacher's academic level/teacher's ability to integrate theory and practice/teaching content course system/teaching methods/teaching style/students' enthusiasm)?

- Are the number of theoretical lectures (Chinese $40 \mathrm{hrs} / \mathrm{MBBS} 56 \mathrm{hrs}$ ) allocated to pathophysiology enough (yes/neutral/no)?

- Are the number of experimental hours allocated to pathophysiology (Chinese $8 \mathrm{hrs} / \mathrm{MBBS} 24 \mathrm{hrs}$ ) enough (yes/neutral/no)? 
- Do you find pathophysiology to be moderately difficult (yes/neutral/no)?

- Do you believe the theory of pathophysiology should be selective in implementing "problem-centered" teaching (yes/neutral/no)?

- Is case analysis necessary for the study of pathophysiology (yes/neutral/no)?

- Is the class discipline good (no eating, speaking, etc.) (yes/neutral/no)?

- Do you actively review the course and complete your homework after the pathophysiology class (yes/neutral/no)?

- Do you want to receive handouts for most the classes (yes/neutral/no)?

- Do you think pathophysiology is hard to learn (yes/neutral/no)?

- Do you have full confidence in your knowledge of pathophysiology (yes/ neutral/no)?

- Do you think classmates' average attendance rate is adequate (yes/neutral/ no)?

- Do you think attending classes is better than self-study (yes/neutral/no)?

- Are you successful in each experiment (yes/neutral/no)?

- Do you take the initiative to operate during an experiment (yes/neutral/no)?

- Do you want teachers to provide "reading outside class" material (yes/neutral/ no)?

- What difficulties or confusion do you have and help to better complete the study of pathophysiology? What is the biggest obstacle?

- Is there something that you would like to tell the teacher?

This questionnaire reflects the current situation of pathophysiology teaching and student's learning in our college comprehensively and objectively. A total of 300 questionnaires were distributed, and 284 valid questionnaires were retrieved, an effective rate of $94.67 \%$. One hundred and seventy-two questionnaires were from Chinese, and 112 were from MBBS students.

\subsection{Data Analysis}

For the valid questionnaires collected, data were analyzed using Sigma Stat 2.03 and Sigma Plot 12.5 software. Chi-square test was used for the comparison between the two groups. $P<0.05$ was considered as statistically significant.

\section{Results}

Quantitative analysis was made on 11 aspects, such as preview, presentation, and experimentation. For the student's self-evaluation, a positive state was given 3 points, a general state was given 2 points, and a negative state was given 1 point. The results are shown in Table 1 and Table 2 and are expressed as a percentage weighted comparison.

\subsection{Horizontal Comparison of Self-Evaluation between the Chinese and MBBS Students}

The MBBS students had better self-confidence than Chinese students in several aspects, except attendance and hands-on experiments. This is probably due to 
Table 1. Horizontal comparison of self-assessment of Chinese and MBBS students.

\begin{tabular}{ccccc}
\hline Preview & 1.72 & 2.25 & 34.332 & $<0.001$ \\
Presentation & 1.99 & 2.10 & 16.854 & $<0.001$ \\
Chapter coherence & 1.84 & 2.38 & 32.541 & $<0.001$ \\
Discipline connection & 1.95 & 2.39 & 25.639 & $<0.001$ \\
Display & 1.77 & 2.46 & 50.254 & $<0.001$ \\
Confidence & 2.35 & 2.57 & 103.985 & $<0.001$ \\
Discipline & 2.37 & 2.79 & 51.166 & $<0.001$ \\
Homework & 2.49 & 2.66 & 21.669 & $<0.001$ \\
Attendance & 2.85 & 2.61 & 40.565 & $<0.001$ \\
Experiment & 2.13 & 2.01 & 53.325 & $<0.001$ \\
Extension & 2.52 & 2.56 & 39.234 & $<0.001$
\end{tabular}

Table 2. Longitudinal comparison of self-assessment of Chinese and MBBS students.

\begin{tabular}{cccc}
\hline Chinese students & \multicolumn{2}{c}{ MBBS students } \\
\hline Attendance & 2.85 & Discipline & 2.79 \\
Extension & 2.52 & Homework & 2.66 \\
Homework & 2.49 & Attendance & 2.61 \\
Discipline & 2.37 & Confidence & 2.57 \\
Confidence & 2.35 & Extension & 2.56 \\
Experiment & 2.13 & Display results & 2.46 \\
Presentation & 1.99 & Discipline & 2.39 \\
Discipline & 1.95 & Chapter coherence & 2.38 \\
Chapter coherence & 1.84 & Preview & 2.25 \\
Display results & 1.77 & Presentation & 2.10 \\
Preview & 1.72 & Experiment & 2.01 \\
\hline
\end{tabular}

cultural differences, Chinese culture influence, and tradition. Chinese students were generally modest when it comes to self-evaluation, while MBBS students were generally more confident. However, this can still reflect the student's cognition of their learning status to a certain extent. MBBS students were better than Chinese students in autonomous learning ability. As for the attendance rate, Chinese students had higher attendance rate than MBBS students. Chinese students had a strong willingness to do experiments and a good completion rate. MBBS students have more confidence in their learning capacities than Chinese students (Table 1).

\subsection{Longitudinal Ranking Analysis of the Two Self-Assessments.}

Punctual attendance is one of the salient points that Chinese students feel they have accomplished. They take their homework seriously and expect that teachers explain the course properly and expand the content if needed. Chinese students feel that the most important thing that needs improvement is preview. In contrast, Chinese students are not active enough to share their learning outcome in 
class, and they are not good at integrating the various chapters of pathophysiology. Most of the students need the teachers' help to conduct a systematic review of knowledge (Table 2).

MBBS students feel that they are very good at self-discipline during class, followed by homework completion, and class attendance. The MBBS students believe that they are weak in experimentation, followed by unsatisfactory classroom presentation, and preview (Table 2).

Base on the Chinese and international medical students' learning habits and other characteristics, the questionnaire concluded the similarities and differences as follows:

\subsection{Before Class}

Nearly half of the students said that they preview sometimes. The proportion of MBBS students with a preview habit was higher than in Chinese students (Figure 1(a)). Chinese students who had the habit of preview usually spent half an hour before each class doing a preview, while MBBS students spent about 0.5 - 2 hours. This could reflect that Chinese medical students have poor autonomous learning ability and weak learning motivation compared to MBBS students. Perhaps, it was also related to the difference in basic knowledge between each other (Figure 1(b)).

\subsection{During Class}

The majority of Chinese and MBBS students were in favor of combining multimedia and blackboard teaching, while the rest of Chinese students were more inclined towards multimedia-based teaching. The rest of the MBBS students had no evident tendency toward multimedia or blackboard-base teaching. This could be related to the difference in speed acceptance due to the language barrier (Figure 2(a)). During the lecture, Chinese students tend to write down and discuss with their classmates after class when they found something they do not understand. In contrast, MBBS students tend to ask questions directly to the

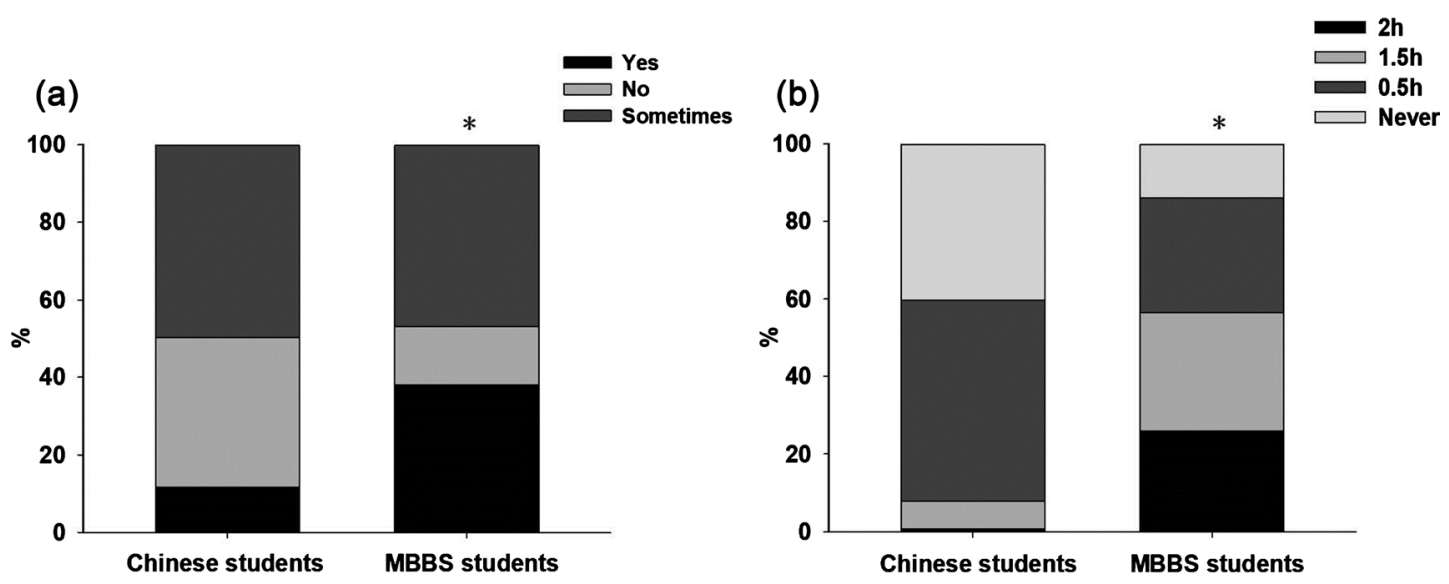

Figure 1. Before the class performances between two groups. (a) Comparison of preview habits $(P<0.001)$; (b) Comparison of preview time $(P<0.001)$. 


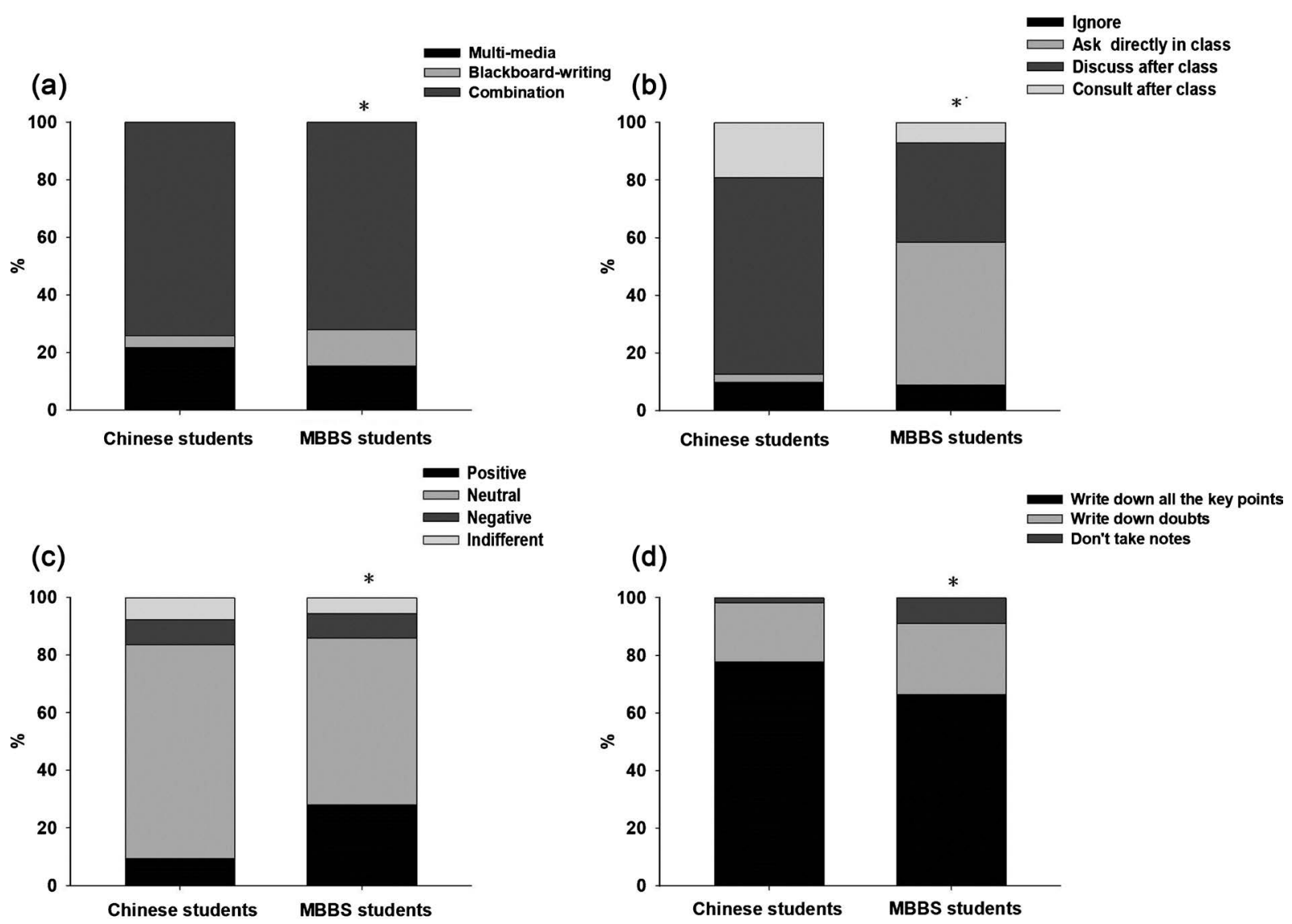

Figure 2. During the class performances between two groups. (a) Tendencies of teaching methods $(P<0.01)$; (b) Comparison of questioning habits $(P<0.001)$; (c) Interactive attitude towards speaking in class $(P<0.001)$; (d) Comparison of note-taking habits $(P<0.01)$.

teacher in class (Figure 2(b)). MBBS students were also more willing to speak in class and interact with teachers than Chinese students (Figure 2(c)). Compared with MBBS students, Chinese students had a strong habit of taking notes during class, and most of them wrote down all the main points, which could reflect the fact that Chinese students are deeply influenced by "indoctrination education". Most of the Chinese students accepted knowledge passively and thought less (Figure 2(d)).

\subsection{After Class}

Chinese students paid equal attention to both reading textbooks and doing exercises after class. While MBBS students paid more attention to textbook reading. Both did not make full use of internet resources (Figure 3(a)). When they encountered problems requiring access to information, they both searched for simple answers through browsers and made little use of professional databases. This could be related to the ability to use learning resources, or it may be related to the fact that there are fewer class hours of pathophysiology. Furthermore, teachers could not guide the subject within the allocated time further. Most of the MBBS students could associate the knowledge of each chapter of pathophysiology 


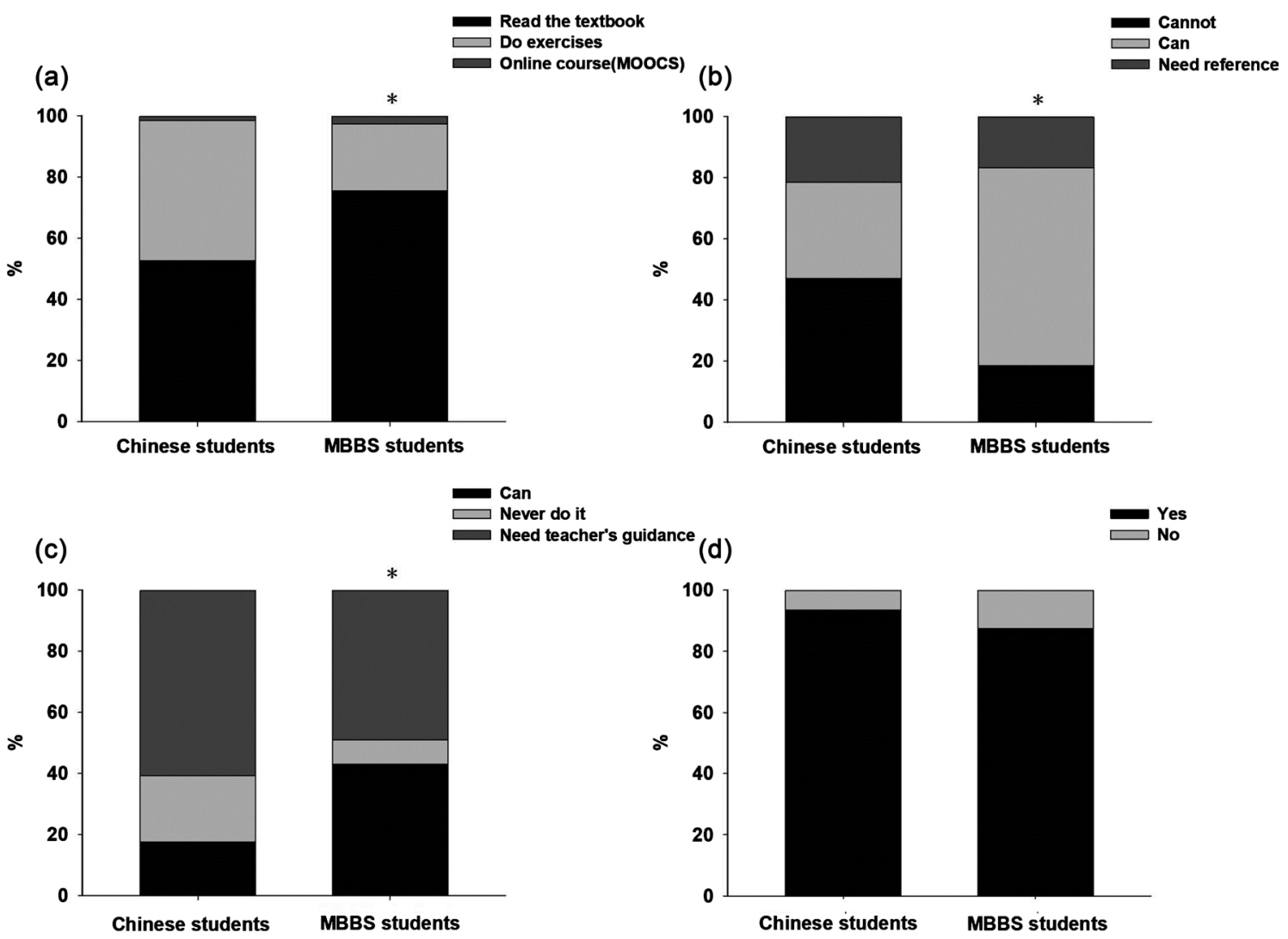

Figure 3. After class performances between two groups. (a) Review style $(P<0.001)$; (b) Pathophysiological chapter interconnection ability $(P<0.001)$; (c) The ability to relate pathophysiology to other disciplines $(P<0.001)$; (d) Chapter test requirements $(P>0.05)$.

independently, while most Chinese students could not or relied on the notes of other peers who were excellent students (Figure 3(b)). About half of the MBBS students could associate pathophysiology independently with pathology, physiology, and other disciplines; while most of the Chinese students did not have this awareness and relied more on teachers. These findings reflect the gap of autonomous learning abilities between the two (Figure 3(c)). Most of them thought it was necessary to do homework or quizzes to help them review each chapter when finished (Figure 3(d)).

\subsection{Curriculum Reform}

Both Chinese and MBBS students tended to combine self-learning, teacher's lecture, and disease-centered discussion in various chapters, which were based on the teacher's lecture. In contrast, Chinese students were more dependent on self-learning. As for the case study, Chinese students were more interested than MBBS students. Both of them expected that case analysis should be given and solved in class.

Most MBBS students preferred to participate in class than Chinese students (Figure 4(a)). The main reason why Chinese students did not want to participate in class is that they were not confident. During classroom presentation, 


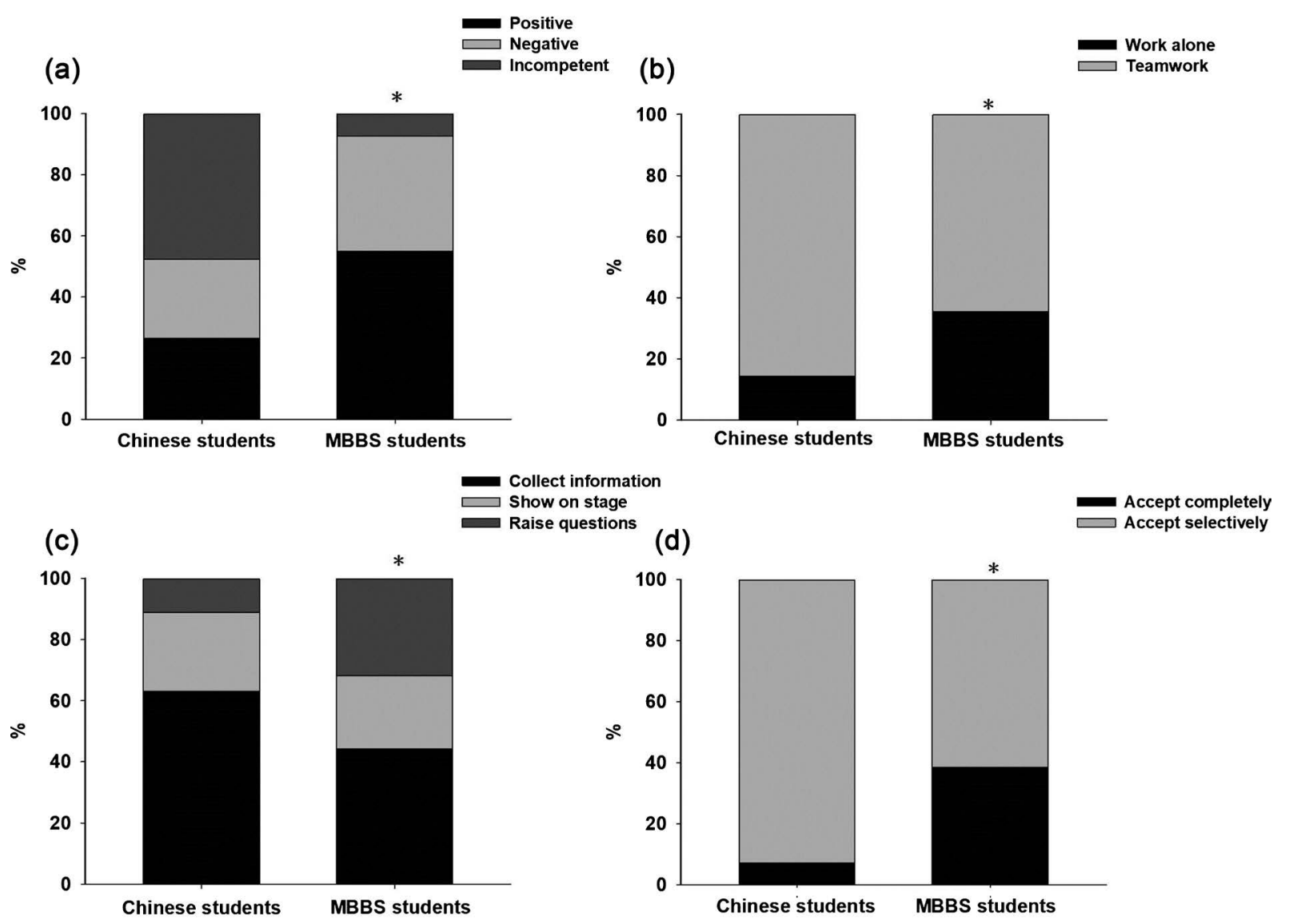

Figure 4. Student participation performances between two groups. (a) Attitude towards showing up $(P<0.001)$; (b) Classroom presentation $(P<0.001)$; (c) Team division preference $(P<0.001)$; (d) Attitudes towards sharing $(P<0.001)$.

both tended to engage in teamwork, but compared with Chinese students, the proportion of MBBS students who chose to complete a task alone was higher (Figure 4(b)). When assigning tasks, students in both groups were willing to collect information, Chinese students participated and spoke in class, while MBBS students tended to raise questions (Figure 4(c)). Regarding student's sharing, the acceptance of Chinese students was lower (Figure 4(d)). This could reflect that Chinese students were not confident enough, and they did not trust other student's learning results or abilities. MBBS students had strong self-confidence and critical thinking.

\subsection{Lab Class}

For functional experiments, both were generally active, although several MBBS students held negative attitudes (Figure 5(a)). When the results of the confirmatory experiments did not meet their expectations, most of the Chinese students preferred to look for the reasons actively, while most of the MBBS students preferred to take the experimental guide as guidance (Figure 5(b)). For experimental reports, more than half of Chinese and MBBS students chose to record and analyze the objective phenomena, but there were still many students choosing to copy the experimental guide (Figure 5(c)). 


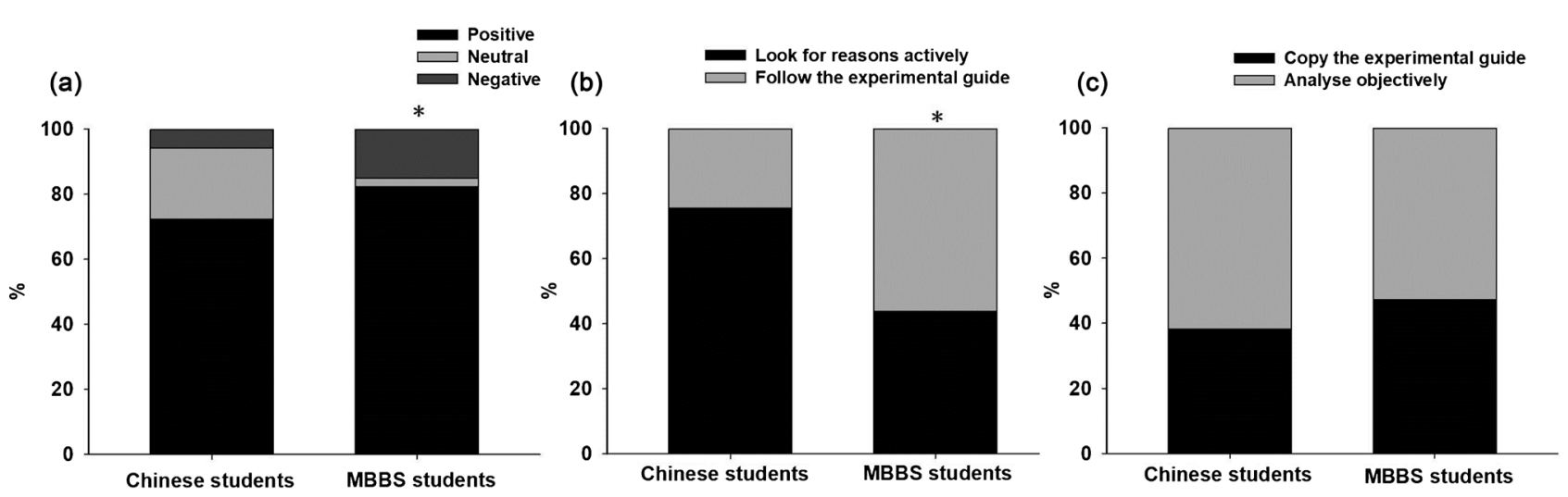

Figure 5. Lab class performances between two groups. (a) Attitudes towards experiments $(P<0.001)$; (b) Attitudes towards unexpected experimental results $(P<0.001)$; (c) Attitudes towards experimental recording $(P>0.05)$.

\subsection{Curriculum Evaluation}

For the theoretical courses and experimental courses assigned to pathophysiology, Chinese students felt that the duration was insufficient, while MBBS students thought it was enough. This was related to the differences in the content of teaching and learning needs between the two student groups. Both thought that the content of the pathophysiology course was moderately difficult and that teachers should provide extra-curricular books and literature, which reflected the students' expectations for further studies of pathophysiology.

\subsection{Self-Cognition}

Most of the MBBS students had clear attitudes towards the evaluation of the current teaching model and learning state, while some Chinese students were ambiguous. This could reflect that the Chinese student's cognition of their learning status was not clear enough, and their learning targets were not distinct enough. To improve the quality of pathophysiology teaching, Chinese students thought that students' enthusiasm was critical, and MBBS students thought that teachers could teach better.

\section{Discussion}

\subsection{Current Situation and Background of Teaching}

Chinese medical students are the best students selected through a demanding college entrance examination. They have a solid foundation of Mathematics, Physics, Chemistry, and there is no language barrier in teaching. The situation of MBBS students is quite different. Most of the MBBS students enrolled in our institute are from Pakistan. Wu (2009) hold same idea that their level of general education is uneven and their basic medical knowledge is scarce. Also, despite having English as their official language for an extended time, they use Urdu to communicate with each other in private. They use English only in class or while talking with Chinese, and Wang (2009) believed that this dialects influence their English pronunciation. Compared with American English and British English 
which Chinese students are used to, their pronunciation is not standard, which affects the communication between teachers and students to a certain extent.

\subsection{Classroom Discipline and Habits}

Chinese students seldom come late, are absent or leave early, and they are disciplined in class. If they have doubts, they will discuss with their classmates after class. If they still cannot solve them, then they will consult with the teacher, and they will not interrupt the teacher's lecture in class. However, the self-discipline of MBBS students is inadequate. They are often late, absent, and even attend classes with food in their hands. In national holydays, they would rather be absent from classes and celebrate, which often disrupts the teaching class. Moreover, Zhu (2010) thought there are some other traits such as unwillingness to clean the experimental materials and classroom in the experimental class, paying too much attention to the test results, and taking many copies in the examination hall.

\subsection{Teaching Mode}

After many years of the teaching reform, higher education in China has made some brilliant achievements, but students still cannot get rid of the shadow of "cramming" completely. Teachers can fully control the teaching process, making explanations and interactions with the classroom. This is an effective teaching model for Chinese students. The current teaching methods of "interactive" "heuristic" "PBL", and "CBL" can arouse the enthusiasm of students to a certain extent, but the traditional teaching model influences them. Chinese students have an awestruck attitude towards teachers. They listen to teachers during the entire lesson and have more restrains when doing questions and classroom interactions. Chinese students show passive learning, weak autonomy, and strong dependence; however, if they do enough exercises before the exam, they can get high scores.

Influenced by Western culture, MBBS students are active in thinking and informal in the classroom. They will initiate interaction actively at any time. When they do not understand a topic during class, they will suddenly say "excuse me" aloud and ask questions, and some might even go to discuss with the teacher directly. For Chinese students, this attitude is considered an impolite behavior in the classroom.

Unfortunately, due to the teaching reform, the hours of pathophysiology have been reduced in recent years. The theoretical hours of Chinese students are 40, and the experimental hours are 8 . The theoretical hours of MBBS students are 56 , and the experimental hours are 24 .

\subsection{Lab Classes}

Pathophysiology is a very hands-on subject. Reproducing pathological models in animals is a feature of functional experiments, and through the practice of pa- 
thophysiology experiment, the Chinese students are more proficient in the basic operation such as ear vein injection, arteriovenous ligation, or tracheal intubation. Moreover, they can cooperate and learn teamwork during these experiments. But when experiments fail, Chinese students are not actively looking for reasons or repeating experiments; instead they are eager to clean up the classroom and finish the experiment. MBBS students have poor hands-on ability, and their experiments are not well performed. They need teachers to demonstrate them step by step so that they can observe and learn the operation more intuitively. Moreover, MBBS students are severely polarized. Students who like to do experiments are more enthusiastic; if they fail, they will find another animal to repeat the experiment. In contrast, some students are reluctant to do the experiments; they rather observe the results.

\subsection{Suggestions for Teaching Improvement}

For the medical education of Chinese students, we should pay special attention to the student's self-confidence and self-learning ability and learn more from the western heuristic and encouraging education methods. Zhang (2016) believed that the healthy competition among students and the learning motivation of Chinese students should be promoted. Teachers should not only guide Chinese students to activate their thinking and expand their knowledge, but also enhance student's participation and interaction through conscious questioning to promote their self-learning ability so that better a teaching effect can be achieved. Also, to address the problem of insufficient class hours, we should increase the class hours appropriately.

For MBBS students, Eliman (2007) thought we should not only respect their national customs and habits, but also strengthen classroom discipline. We should include attendance as part of their usual assessment. Every international student has a different education background before entering college. Therefore, we should refer to international teaching evaluation methods to evaluate MBBS students, and divide their grades into $\mathrm{ABC}$ instead of a percentage. The evaluation system should be focused on the student's study atmosphere and knowledge acquisition. $\mathrm{Ma}$ (2007) thought desalination of the actual score system for medical MBBS students can promote a mutual benefit in teaching. Mao (2017) and Huang (2005) thought in experimental courses, Chinese and MBBS students can try to cooperate and learn from each other, to enhance the discipline, hygiene habits, and hands-on ability of MBBS students, as well as the ability of Chinese students to communicate in English and ask questions. Chen (2006) thought in experimental teaching, if there is an assistant teacher besides the lecturer, the teaching effect can be improved from a teaching point of view as it can increase the chances of practical exercise, and also from the teacher's point of view. Regarding the poor organizational discipline of MBBS students, their attendance, experiment operation skills, and experiment report, these should be closely related to the experiment course grades. At the same time, they should be told 
about the importance of punctuality, Zhu (2008) thought this is one of the basic requirements for a qualified doctor.

Teachers should associate the improvement of English with the teaching quality, take advantage of their time, and strengthen their English speaking. Furthermore, Chen (2007) thought teachers should be familiar with the medical terms involved in their subject and have a good command of English expressions and sentence patterns during the course. Wang (2013) and Liu (2012) thought that international students in China have Chinese courses in their freshman year, and their spoken Chinese can reach a level of barrier-free communication in their junior year. It is better for teachers to use bilingual teaching in class because most teachers express better in Chinese than in English. Besides, due to different geographical characteristics of each country and the epidemiological characteristics of diseases, frequently-occurring diseases are different. We should let MBBS students master the common diseases of their country. In theoretical lessons, teachers should pay attention to explaining fundamental concepts and theories in detail and thoroughly, citing more real-life examples to arouse student's interests. Wang (2011) thought more questions should be asked to assess the student's mastery of fundamental concepts.

According to the information obtained from the questionnaire, both Chinese and MBBS students hope to take the chapter test in order to evaluate their study status. Teachers are expected to give bibliographies and literature before class, introduce the current progress of the subject in class, understand the dynamics of the subject, and promote interest in learning.

\section{Conclusion}

With the development of the "Belt and Road" construction, the state has paid unprecedented attention to higher education reform and opening. Yang (2019) thought the internationalization of higher education has enabled a historic opportunity for development. International student education is an integral part of higher education in China while research is still in its infancy. There is an excellent opportunity for improvement, which requires joint efforts by teachers. At the same time, the advantages of MBBS students can guide the teaching of Chinese medical students. Making a comparative analysis of the two, learning from each other's strengths, and complementing each other's weaknesses, can help to develop a useful teaching model, and improve the quality of education.

\section{Ethics Approval and Consent to Participate}

The project was approved by the Human Research Ethics Committee at the University of Yangtze. Students were informed about the study and signed consent forms.

\section{Availability of Data and Materials}

The dataset used and/or analysed during the current study is available from the 
corresponding author on reasonable request.

\section{Funding}

This study was supported by the Nature Science Foundation of Hubei Province (2017CFB786), Hubei Province Health and Family Planning Scientific Research Project (WJ2016Y10), Jingzhou Science and Technology Bureau Project (2017-93), and scientific research project supported by Hubei Jikang Pharmaceutical Co., Ltd. (2018H230); all funding belonged to Dr Peng.

\section{Authors' Contributions}

KHW contributed to the conception and design of the study, acquisition, analysis and interpretation of the data and the initial drafting and final revision of the manuscript. Both YZ and DSL contributed to the conception and design of the study, QZ, SAK, XCP contributed to the interpretation of the data and to the final revision of the manuscript for important intellectual content. All authors read and approved the final manuscript.

\section{Conflicts of Interest}

The authors declare no conflicts of interest regarding the publication of this paper.

\section{References}

Chen, N. (2006). Teaching Practice and Experience of Foreign Students in Pathophysiology. Journal of Shanxi Medical University (Basic Medical Education Edition), 8, 132-133.

Chen, X. X. (2007). Experience in Physiology Teaching for Foreign Students. Exploration of Medical Education, 6, 708-709.

Eliman, A. (2007). A Preliminary Study on the Cross-Cultural Management Model of Overseas Students from Central Asia in China. Journal of Xinjiang Normal University, 4, 74-77.

Huang, M. (2005). The Influence of Foreign Students Training on Medical Students' Education. Journal of Dalian Medical University, 6, 248-250.

Liu, X. (2012). Discussion on Ethical Education for Medical Overseas Student. Chinese Medical Ethics, 6, 384-385.

Ma, Q. Y. (2007). How to Strengthen Clinical Medical Education for Undergraduate Foreign Students. Northwest Medical Education, 15, 3-342.

Mao, J. H. (2017). Experiences of Synchronizing Experimental Teaching between Chinese Students and Foreign Students in Order to Promote Bilingual Teaching and Foreign Students' Teaching. Science and Technology Perspective, No. 24, 33-34.

Wang, J. (2009). A Preliminary Study on the Teaching Method of Medical English for South Asian Students. Journal of Nantong University, 12, 91-93.

Wang, L. F. (2011). Probing into Solving Understanding Obstacles of foreign Students in Physiology Teaching. Basic Medical Education, 13, 763-765.

Wang, Z. W. (2013). Some Thoughts on the Education of Overseas Students in Stomatology. Papers of the Ninth National Symposium on Stomatological Education, No. 8, 
$487-488$

Wu, J. X. (2009). Teaching Practice and Exploration of Basic Medical Course for South Asian Students. Researches in Medical Education, 5, 551-553.

Yang, L. R. (2019). Exploring the Management Mechanism of Overseas Students in Vocational Colleges under the Background of "Belt and Road". Think Tank Era, No. 31, 3-5.

Zhang, C. H. (2012). Comparison between Foreign Students and Chinese Students in Practical Teaching of Pathophysiology. Extracurricular Education in China, 2, 103.

Zhang, Y. (2016). A Comparative Study of Learning Motivation and Influencing Factors between Chinese Medical Students and Foreign Students. Chinese Journal of Medical Education, 36, 530-533.

Zhao, L. J. (2011). Comparison of Pathophysiology Teaching between Foreign Students and Chinese Students. Higher Medical Education in China, 1, 7-8.

Zhu, H. (2010). Overcoming Cultural Differences and Improving the Quality of Physiology Classroom Teaching for Foreign Students. Journal of Clinical and Experimental Medicine, 9, 1279.

Zhu, L. (2008). Flexible Management in Physiology Teaching for Foreign Students to Overcome Cultural Differences. China's Medical Frontier, 3, 65-66. 